\title{
Potential compression of the musculocutaneous, median and ulnar nerves by a very rare variant of the coracobrachialis longus muscle
}

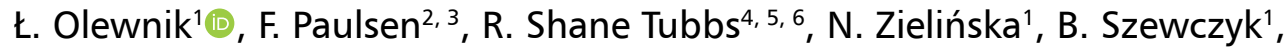 \\ P. Karauda ${ }^{1}$, M. Polguj ${ }^{7}$ \\ 'Department of Anatomical Dissection and Donation, Medical University of Lodz, Poland \\ 2Institute of Functional and Clinical Anatomy, Friedrich Alexander University Erlangen-Nürnberg, Erlangen, Germany \\ ${ }^{3}$ Department of Topographic Anatomy and Operative Surgery, Sechenov University, Moscow, Russia \\ ${ }^{4}$ Department of Neurosurgery, Tulane University School of Medicine, New Orleans, LA, United States \\ ${ }^{5}$ Department of Neurosurgery and Ochsner Neuroscience Institute, Ochsner Health System, New Orleans, \\ LA, United States \\ ${ }^{6}$ Department of Anatomical Sciences, St. George's University, Grenada \\ 'Department of Normal and Clinical Anatomy, Medical University of Lodz, Poland
}

[Received: 18 July 2020; Accepted: 21 July 2020; Early publication date: 22 August 2020]

\begin{abstract}
The coracobrachialis longus muscle $(C B L)$ is an extremely rare variant of the coracobrachialis muscle (CRM). The CBL originates from the apex of the coracoid process together with the short head of the biceps brachii and inserts on the olecranon of the ulna. The CBL consists of three parts: a superior part (classical $C R M$ - length $137.88 \mathrm{~mm})$, a middle fibrous layer $(23.41 \mathrm{~mm})$, and an inferior part $(185.37 \mathrm{~mm}$ ). A rare relationship between the CBL and median, musculocutaneous and ulnar nerves was observed with potential compression at these three parts. In addition, this case report describes a connection between CBL and the medial head of the triceps brachii, as well as a third head of the biceps brachii, which originate from the fibrous layer. This case report highlights the relationships between the CBL and the median, ulnar and musculocutaneous nerves. (Folia Morphol 2021; 80, 3: 707-713)
\end{abstract}

Key words: anatomical variations, coracobrachialis longus muscle, median nerve, musculocutaneous nerve, ulnar nerve

\section{INTRODUCTION}

The coracobrachialis muscle (CRM) originates from the apex of the coracoid process of the scapula in common with the short head of the biceps brachii muscle. It inserts by means of a flat, short tendon into the medial surface of the humerus, between the attachments of the triceps brachii and brachialis muscles [36].

The musculocutaneous nerve ( $\mathrm{MCN}$ ) arises from the lateral cord of the brachial plexus and contains fibres from the $\mathrm{C} 5-\mathrm{C} 7$ ventral rami. The MCN passes through the CRM and descends between the biceps brachii and brachialis muscles both of which it innervates [35]. The median nerve (MN) arises from the medial and lateral cords of the brachial plexus and is innervated by the $\mathrm{C6}, \mathrm{C7}, \mathrm{C8}$ and $\mathrm{T} 1$ ventral rami [35]. The MN provides motor and sensory function to the forearm and hand [35]. The ulnar nerve (UN) is comprised of $\mathrm{C} 8$ and $\mathrm{T} 1$ ventral rami. The UN innervates

Address for correspondence: Ł. Olewnik, MD, PhD, Department of Normal and Clinical Anatomy, Interfaculty Chair of Anatomy and Histology, Medical University of Lodz, ul. Narutowicza 60, 90-136 Łódź, Poland, e-mail: lukasz.olewnik@umed.lodz.pl

This article is available in open access under Creative Common Attribution-Non-Commercial-No Derivatives 4.0 International (CC BY-NC-ND 4.0) license, allowing to download articles and share them with others as long as they credit the authors and the publisher, but without permission to change them in any way or use them commercially. 
two muscles of the forearm, the flexor carpi ulnaris and ulnar half of the flexor digitorum profundus. It has branches extending to the hand over the distal forearm and wrist [35].

Many earlier works describe the various types of morphological variations occurring within this CRM. They mainly concern the morphological variability of the proximal and distal attachment, but also additional bands or the occurrence of additional muscle bellies or heads $[4,16-18,24,27,32]$. However, little is reported for one of its variants, the coracobrachialis longus muscle (CBL). While Wood [51] was probably the first to describe such a variant in 1867, a similar discovery was made by Kyou-Jouffroy et al. [30]. A description of the $C B L$ was more recently made by Georgiev et al. [18].

Morphological variations have been previously observed between the CRM and even the MCN or $\mathrm{MN}$. The presence of an extra muscle head or belly can place pressure on the MCN or proximal MN. More importantly, the presence of the CBL can place pressure on the MCN, MN or UN.

Peripheral neuropathies can be classified as compressive/entrapment and non-compressive forms $[2,11]$. Although peripheral nerve compression or entrapment is possible anywhere along the course of a nerve, it tends to occur more often where the nerve passes through fibro-osseous or fibromuscular tunnels or penetrates muscles $[11,26]$.

This study describes a very rare and undescribed variation of the $C B L$ and its extremely rare relationship with the MN, MCN and UN. Knowledge of such a very rare type can make it easier to understand disease in this region and improve its treatment.

\section{CASE REPORT}

The left upper limb from a male cadaver that was 78-year-old at death underwent routine anatomical dissection for research and teaching purposes in the Department of Anatomical Dissection and Donation, Medical University of Lodz, Poland [38, 45, 46].

\section{Morphology of the coracobrachialis longus muscle}

The proximal part of the CRM corresponded to the classical description, and originated from the apex of the coracoid process together with the short head of the biceps brachii. The width of the muscle belly origin was $9.94 \mathrm{~mm}$, while the thickness was $4.13 \mathrm{~mm}$. The length of the belly muscle was

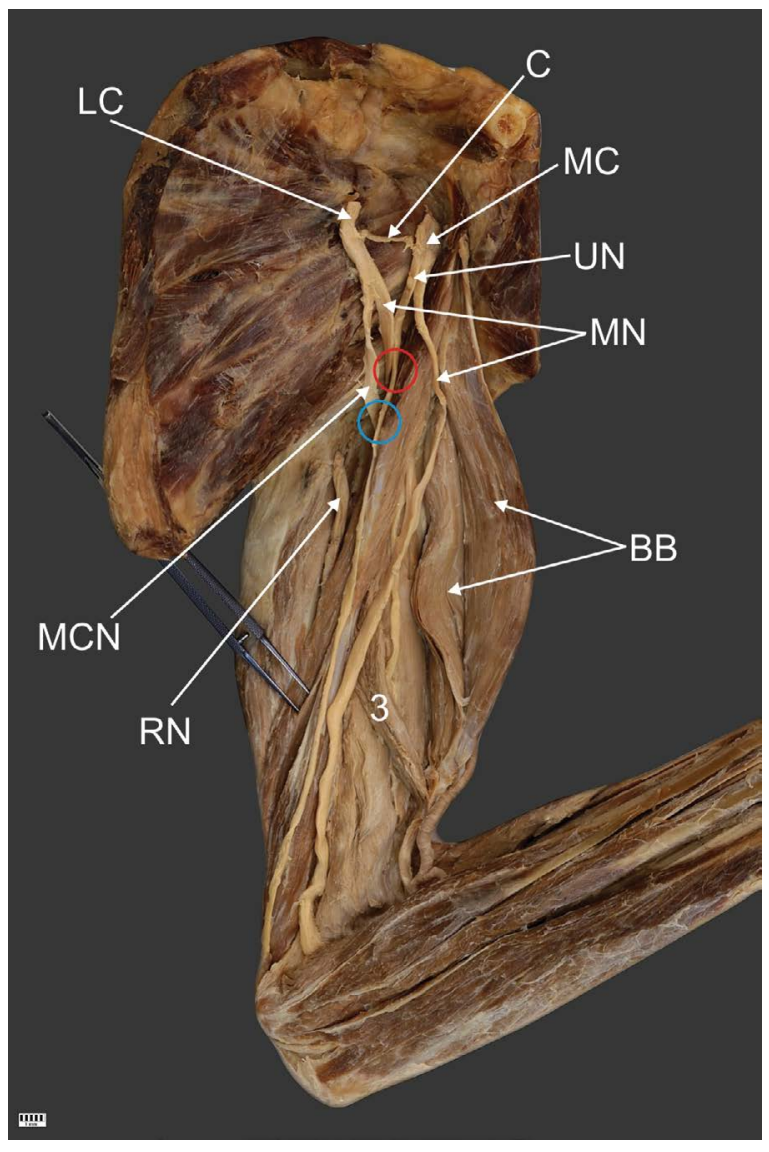

Figure 1. The coracobrachialis longus muscle and relation to the median and musculocutaneous nerve; LC - lateral cord of the brachial plexus; $\mathrm{MC}$ - medial cord of the brachial plexus; $\mathrm{C}$ communicating branch; UN — ulnar nerve; $\mathrm{MN}$ - median nerve; $\mathrm{MCN}$ - musculocutaneous nerve; RN — radial nerve; $\mathrm{BB}$ - biceps brachii; 3 - third head of the biceps brachii. The red circle shows the potential compression site of the median nerve, while the blue circle shows the potential compression site of the musculocutaneous nerve.

$137.88 \mathrm{~mm}$. The muscle then inserted on the medial surface of the shaft of the humerus between the attachments of the triceps brachii and brachialis muscles. This part continued as a thin fibrous layer (length $-23.41 \mathrm{~mm}$ ) with the second part of the muscle (Fig. 1). The length of the muscle belly was $185.37 \mathrm{~mm}$; the muscle belly passed the tendon (13.95 $\mathrm{mm}$ length) and inserted on the olecranon of the ulna. The distal part of the CBL connected with the brachii triceps tendon (Fig. 2). The thin fibrous layer included an accessory band (length $25.83 \mathrm{~mm}$ ) that connected to the medial head of the triceps brachii, and the thin fibrous layer was the origin of the third head of the biceps brachii muscle (Figs. 1, 3). 




Figure 2. Distal part of the arm. Insertion of the coracobrachialis longus muscle; LaHTB — lateral head of the triceps brachii; LHTB - long head of the triceps brachii; MTB - medial head of the triceps brachii; $\mathrm{CBL}$ - coracobrachialis longus muscle; 0 - olecranon of the ulna; ME — medial epicondyle; UN — ulnar nerve. The white arrowheads show the potential compression site of the ulnar nerve.

\section{CBL relation to $\mathrm{MN}, \mathrm{MCN}$ and $\mathrm{UN}$}

Median nerve. The MN arose from both the lateral and medial cords of the brachial plexus. The lateral cord fibres travelled under the CBL and then connected with those arising from the medial cord of the brachial plexus. After $100.09 \mathrm{~mm}$, the lateral cord fibres combined with the medial cord fibres. The medial cord fibres were $97.2 \mathrm{~mm}$ in length. The CBL was in the characteristic loop of the MN. The MN passed under the muscle and had a diameter of $5.10 \mathrm{~mm}$, while the $\mathrm{CBL}$ at this point was $28.36 \mathrm{~mm}$ wide and $3.31 \mathrm{~mm}$ thick (Fig. 1).

Musculocutaneous nerve. The MCN arose from the lateral cord of the brachial plexus and passed under the $C B L$ at a point $53.25 \mathrm{~mm}$ from the place of origin. The MCN passed under the muscle and had a diameter of $4.95 \mathrm{~mm}$, while the CBL at this point was $21.95 \mathrm{~mm}$ wide and $3.19 \mathrm{~mm}$ thick (Fig. 1).

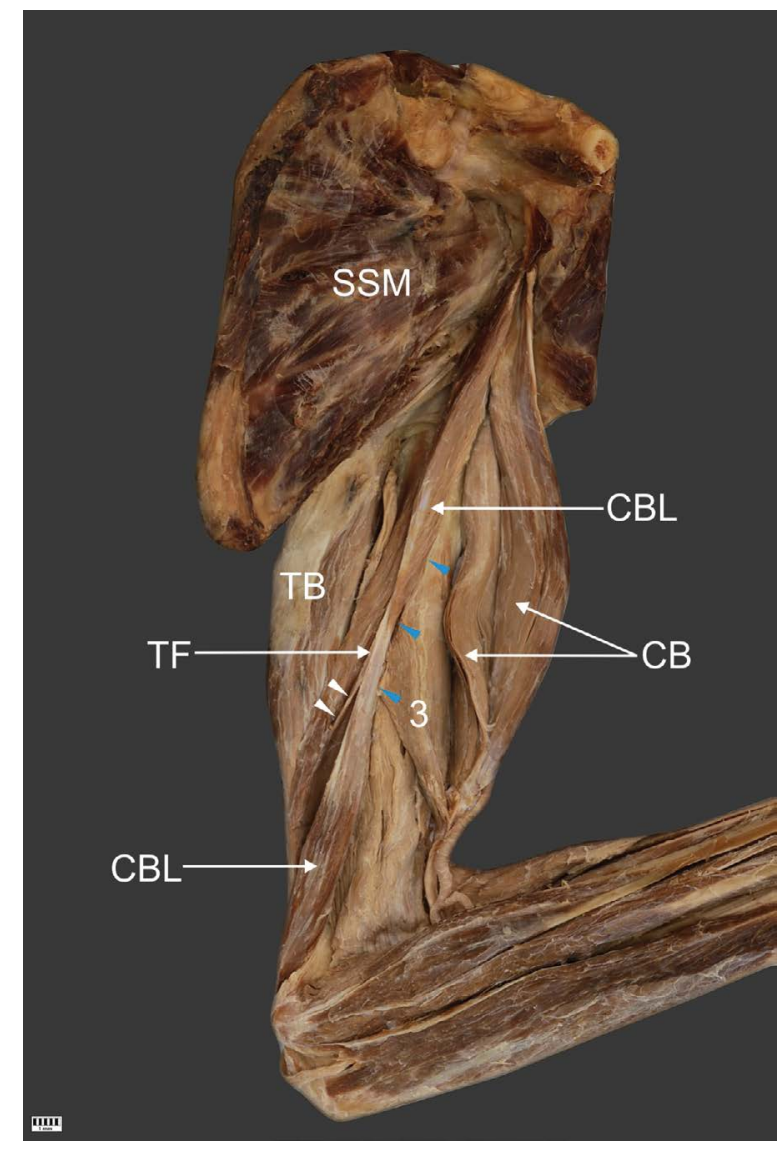

Figure 3. Coracobrachialis longus muscle. Nerves are removed to reveal the coracobrachialis longus muscle; SSM - subscapularis muscle; $\mathrm{CBL}$ - coracobrachialis longus muscle; $\mathrm{BB}$ - biceps brachii; 3 - third head of the biceps brachii; TB - triceps brachii; TF - tendinous fibrous. The white arrowheads show the slip of the coracobrachialis longus muscle which attaches to the medial head of the triceps brachii. Blue arrowheads show the place of origin of the third head of the biceps brachii.

Ulnar nerve. The UN arose from the medial cord of the brachial plexus, and ran along the CRM, lying exactly on top of it; in the distal part, it was located between the CBL and medial epicondyle, with a diameter of $2.85 \mathrm{~mm}$, while the CBL at this point was $8.90 \mathrm{~mm}$ wide and was 3.31 thick (Fig. 2).

Detailed morphometric measurements were taken. After photographic documentation, the CRM was carefully dissected in order to minimise any errors in measurement. The measurements were performed using two methods:

- with an electronic calliper (Mitutoyo Corporation, Kawasaki-shi, Kanagawa, Japan). Each measurement was carried out twice with an accuracy of up to $0.1 \mathrm{~mm}$;

- an analysis of digital photographic images was processed using MultiScanBase 18.03 (Computer 
Scanning System II, Warsaw, Poland). The value and precision of this method have been confirmed in previous studies [20, 29, 40,42].

The posterior cord of the brachial plexus was removed to more accurately visualise the neuromuscular structures described in this case. The variant muscle was innervated by the MCN. No medical or surgical history of the cadaver was available. No similar variation was observed in the contralateral upper limb.

\section{DISCUSSION}

Embryologically, the biceps brachii, CRM, and brachialis muscle are intimately fused together at a very early stage and probably arise from a common premuscle mass. The origins of the two heads of the biceps brachii at this early stage are close together and only become separated with the later growth of the scapula. The three muscles can be recognized in embryos 14 to $16 \mathrm{~mm}$ in length, and the tendon of the long head in embryos of $14 \mathrm{~mm}$ in length. The distal end of the common muscle mass differentiates later than the proximal end $[3,47]$. The presence of the CBL could be explained as a result of the premature termination of this regression process.

The CRM is characterised by variability in both proximal and distal attachments. Variations regarding additional heads of this muscle are uncommon $[8,12-14,17,18,24,51]$ and the CBL itself has been described much less often $[5,18,51,52]$. The CBL might attach to the humerus, to a fibrous band of the medial intramuscular septum, i.e. Struthers' ligament, or to the medial epicondyle $[5,18,51$, $52]$, it may also insert to the tendinous part of the latissimus dorsi $[5,51]$.

The current study describes an extremely rare type of CBL. The proximal attachment was identical to the normal CRM; however, its distal attachment was not located on the humerus, medial intramuscular septum, Struthers' ligament, medial epicondyle or latissimus dorsi but only on the olecranon of the ulna. In the present study, the thin fibrous layer is characteristic, from which an additional CBL band begins, connecting it to the medial head of the triceps brachii, and gives rise to the origin of the third head of the biceps brachii (Figs. 1, 3).

Recent years have seen a growth in the diagnosis of neuropathies occurring as a consequence of nerve entrapment or compression by muscles. These conditions are most commonly observed in the upper limb and most commonly involve the $\mathrm{MN}, \mathrm{UN}$, radial nerve or MCN [6, 9-11, 19, 21-23, 33, 38, 39, 41, 43].

Musculocutaneous nerve neuropathy is not as common as MN or UN neuropathy. Most often, it is due to muscular compression by the CRM, biceps brachii, or brachialis muscles $[1,5,7,12-14,28,37$, $49,50]$. The course of the MCN is closely related to that of the CRM. The MCN can pierce or pass deep to the CRM $[12,15,24,31,48]$. It is believed that the CRM is the most common site of MCN entrapment and additional heads can place pressure on the $\operatorname{MCN}[4,14,16,17,27,32]$. A potential site of $M C N$ entrapment was also observed in the present case: at this point, $53.25 \mathrm{~mm}$ from its origin, the MCN (4.95 $\mathrm{mm}$ in diameter) passed under the CBL with the CRM being $21.95 \mathrm{~mm}$ in width and $3.19 \mathrm{~mm}$. MN entrapment within the CRM muscle leads to weakness and atrophy of the biceps brachii and brachialis muscles and a loss of sensation in the lateral forearm. Active young individuals that frequently engage in shoulder and elbow flexion with the forearm in a pronated position are most susceptible [44]. It also often occurs following chronic overuse of the CRM and consequent hypertrophy. The nerve compressed within the CRM has already given off its motor branch to the CRM, therefore no loss of CRM muscle function will be observed.

Median nerve compression can occur at various sites along its course $[2,33]$. The most common type of MN neuropathy is carpal tunnel syndrome [11, 33]. The next most common site of MN compression is at the pronator teres i.e., pronator teres syndrome, symptoms of which can be manifested by entrapment of MN between the humeral and ulnar heads of the pronator teres muscle [38]. MN compression in the arm is much less common and when present, is due to compression by Struthers' ligament i.e., supracondylar process syndrome $[25,38]$. Supracondylar process syndrome is one of the rarest types of $\mathrm{MN}$ neuropathy at about $0.5 \%[33,34]$. MN compression can also occur with the presence of a third head of the biceps brachii [53]; lastly, MN compression can occur more proximal in the arm, with additional heads of the CRM $[13,31]$, and the additional head of the CRM causing compression of the lateral cord of the brachial plexus [16].

Another potential site of MN entrapment was also identified in the present study. The MN had a diameter of $5.10 \mathrm{~mm}$ when passing under the muscle, while the CBL at this point was $28.36 \mathrm{~mm}$ wide and 
$3.31 \mathrm{~mm}$ thick. Complaints from compression of the MN by a CBL include loss of fine motor skills and a burning sensation or numbness in the palm.

The second most commonly seen entrapment neuropathy of the upper limb after carpal tunnel syndrome is UN neuropathies. The UN passes over the lateral wall of the axilla and passes to the medial side of the arm. It enters into the groove for the UN behind the medial epicondyle $[5,35]$. This groove is the most common entrapment site of the UN. Interestingly, in the current case, the distal part of the CBL might also cause UN compression at the level of the medial epicondyle. At this location, the UN was found to have a diameter of $2.85 \mathrm{~mm}$, while the CBL at this point was $8.90 \mathrm{~mm}$ wide and 3.31 thick; any hypertrophy of this muscle could cause compression. UN neuropathy at the elbow can be recognized by numbness of the $4^{\text {th }}$ and $5^{\text {th }}$ digits, hypoesthesia of the medial palm, atrophy and paraesthesia of the hand muscles innervated by the UN.

\section{CONCLUSIONS}

The present case report describes a very rare variant of the $C B L$ and its relationship between the MN, MCN and UN. Unfortunately, due to the lack of an adequate number of descriptions of such a rare muscle, confusion may occur during surgery, and the assessment of imaging of this region may be complicated. A greater understanding of the potential compression sites of individual nerves is needed for the correct diagnosis of unrecognised compression sites, and such knowledge of rare variations is an essential part of every clinician's daily practice.

The CBL can have anatomical variants. Along its course, compression of the MN, MCN and UN can occur. Knowledge of such rare muscle variations and their relation to the MN, UN and MCN is required for effective daily clinical practice.

\section{Ethical approval and consent to participate}

The cadaver belonged to the Department of Anatomical Dissection and Donation, Medical University of Lodz, Poland.

\section{Conflict of interest: None declared}

\section{REFERENCES}

1. Abu-Hijleh MF. Three-headed biceps brachii muscle associated with duplicated musculocutaneous nerve. Clin Anat. 2005; 18(5): 376-379, doi: 10.1002/ca.20100, indexed in Pubmed: 15971222.
2. Andreisek G, Crook DW, Burg D, et al. Peripheral neuropathies of the median, radial, and ulnar nerves: MR imaging features. Radiographics. 2006; 26(5): 1267-1287, doi: 10.1148/rg.265055712, indexed in Pubmed: 16973765.

3. Bardeen C. Studies of the development of the human skeleton. Am J Anat. 1905: 265-302.

4. Bauones S, Moraux A. The accessory coracobrachialis muscle: ultrasound and MR features. Skeletal Radiol. 2015; 44(9): 1273-1278, doi: 10.1007/s00256-015-2153-1, indexed in Pubmed: 25924580.

5. Bergman R, Afifi A, Miyauchi R. Illustrated encyclopedia of human anatomic variations. Anatomy Atlas 2017.

6. Besleaga D, Castellano V, Lutz C, et al. Musculocutaneous neuropathy: case report and discussion. HSS J. 2010; 6(1): 112-116, doi: 10.1007/s11420-009-9143-6, indexed in Pubmed: 20013159.

7. Catli MM, Ozsoy U, Kaya Y, et al. Four-headed biceps brachii, three-headed coracobrachialis muscles associated with arterial and nervous anomalies in the upper limb. Anat Cell Biol. 2012; 45(2): 136-139, doi: 10.5115/ acb.2012.45.2.136, indexed in Pubmed: 22822469.

8. Chouke KS. Variation of the coracobrachialis muscle. Anat Rec. 1924; 27(3): 157-163, doi: 10.1002/ar.1090270303.

9. Claassen $H$, Schmitt $O$, Wree $A$, et al. Variations in brachial plexus with respect to concomitant accompanying aberrant arm arteries. Ann Anat. 2016; 208: 40-48, doi: 10.1016/j.aanat.2016.07.007, indexed in Pubmed: 27507152.

10. Davidson JJ, Bassett FH, Nunley JA. Musculocutaneous nerve entrapment revisited. J Shoulder Elbow Surg. 1998; 7(3): 250-255, doi: 10.1016/s1058-2746(98)90053-2, indexed in Pubmed: 9658350.

11. Dong Q, Jacobson JA, Jamadar DA, et al. Entrapment neuropathies in the upper and lower limbs: anatomy and MRI features. Radiol Res Pract. 2012; 2012: 230679, doi: 10.1155/2012/230679, indexed in Pubmed: 23125929.

12. El-Naggar MM. A study on the morphology of the coracobrachialis muscle and its relationship with the musculocutaneous nerve. Folia Morphol. 2001; 60(3): 217-224, indexed in Pubmed: 11552663.

13. El-Naggar MM, Al-Saggaf S. Variant of the coracobrachialis muscle with a tunnel for the median nerve and brachial artery. Clin Anat. 2004; 17(2): 139-143, doi: 10.1002/ ca.10213, indexed in Pubmed: 14974102.

14. El-Naggar MM, Zahir FI. Two bellies of the coracobrachialis muscle associated with a third head of the biceps brachii muscle. Clin Anat. 2001; 14(5): 379-382, doi: 10.1002/ ca.1067, indexed in Pubmed: 11754228.

15. Flatow EL, Bigliani LU, April EW. An anatomic study of the musculocutaneous nerve and its relationship to the coracoid process. Clin Orthop Relat Res. 1989; NA(244): 166-171, doi: 10.1097/00003086-198907000-00014.

16. Garbelotti SA, Marques SR, Rocha PR, et al. An unusual case of accessory head of coracobrachialis muscle involving lateral cord of brachial plexus and its clinical significance. Folia Morphol. 2017; 76(4): 762-765, doi: 10.5603/FM.a2017.0033, indexed in Pubmed: 28353299.

17. Georgiev GP, Landzhov B, Tubbs RS. A novel type of coracobrachialis muscle variation and a proposed new classification. Cureus. 2017; 9(7): e1466, doi: 10.7759/ cureus.1466, indexed in Pubmed: 28936378. 
18. Georgiev GP, Tubbs RS, Landzhov B. Coracobrachialis longus muscle: humeroepitrochlearis. Cureus. 2018; 10(5): e2615, doi: 10.7759/cureus.2615, indexed in Pubmed: 30027007.

19. Gillingham BL, Mack GR. Compression of the lateral antebrachial cutaneous nerve by the biceps tendon. J Shoulder Elbow Surg. 1996; 5(4): 330-332, doi: 10.1016/ s1058-2746(96)80062-0, indexed in Pubmed: 8872933.

20. Gonera B, Kurtys K, Karauda P, et al. Possible effect of morphological variations of plantaris muscle tendon on harvesting at reconstruction surgery-case report. Surg Radiol Anat. 2020; 42(10): 1183-1188, doi: 10.1007/ s00276-020-02463-1, indexed in Pubmed: 32248255.

21. Green JR, Rayan GM. The cubital tunnel: anatomic, histologic, and biomechanical study. J Shoulder Elbow Surg. 1999; 8(5): 466-470, doi: 10.1016/s1058-2746(99)900782, indexed in Pubmed: 10543601.

22. Halac G, Topaloglu P, Demir S, et al. Ulnar nerve entrapment neuropathy at the elbow: relationship between the electrophysiological findings and neuropathic pain. J Phys Ther Sci. 2015; 27(7): 2213-2216, doi: 10.1589/ jpts.27.2213, indexed in Pubmed: 26311956.

23. Hayashi M, Shionoya K, Hayashi S, et al. A novel classification of musculocutaneous nerve variations: The relationship between the communicating branch and transposed innervation of the brachial flexors to the median nerve. Ann Anat. 2017; 209: 45-50, doi: 10.1016/j. aanat.2016.08.004, indexed in Pubmed: 27765675.

24. Ilayperuma I, Nanayakkara BG, Hasan R, et al. Coracobrachialis muscle: morphology, morphometry and gender differences. Surg Radiol Anat. 2016; 38(3): 335-340, doi: 10.1007/s00276-015-1564-y, indexed in Pubmed: 26464302.

25. De Jesus R, Dellon AL. Historic origin of the "Arcade of Struthers". J Hand Surg Am. 2003; 28(3): 528-531, doi: 10.1053/jhsu.2003.50071, indexed in Pubmed: 12772116.

26. Kim SJ, Hong SH, Jun WS, et al. MR imaging mapping of skeletal muscle denervation in entrapment and compressive neuropathies. Radiographics. 2011; 31(2): 319-332, doi: 10.1148/rg.312105122, indexed in Pubmed: 21415181.

27. Kopuz C, Içten N, Yildirim M. A rare accessory coracobrachialis muscle: a review of the literature. Surg Radiol Anat. 2003; 24(6): 406-410, doi: 10.1007/s00276-002-0079-5, indexed in Pubmed: 12652369.

28. Kosugi K, Shibata S, Yamashita H. Supernumerary head of biceps brachii and branching pattern of the musculocutaneus nerve in Japanese. Surg Radiol Anat. 1992; 14(2): 175-185, doi: 10.1007/BF01794898, indexed in Pubmed: 1641744.

29. Kurtys K, Gonera B, Olewnik $t$, et al. A highly complex variant of the plantaris tendon insertion and its potential clinical relevance. Anat Sci Int. 2020; 95(4): 553-558, doi: 10.1007/s12565-020-00540-4, indexed in Pubmed: 32248353

30. Kyo-Jouffroy M, Lessertisseur J, Saban R, Souteyrand-Boulenger J. Musculature des membres, membre pectoral, groupe branchial ventral. In: Traite de zoologie, mammiferes. Masson, Paris 1971.

31. Loukas M, Aqueelah H. Musculocutaneous and median nerve connections within, proximal and distal to the cora- cobrachialis muscle. Folia Morphol. 2005; 64(2): 101-108, indexed in Pubmed: 16121328.

32. Mestdagh H, Maynou C, Cassagnaud X. Accessory coracobrachialis muscle as a cause of anterior impingement syndrome of the rotator cuff in an athlete. Eur J Orthop Surg Traumatol. 2002; 12(2): 96-98, doi: 10.1007/s00590002-0021-x, indexed in Pubmed: 24570160.

33. Meyer $P$, Lintingre $P F$, Pesquer $L$, et al. The median nerve at the carpal tunnel ... and elsewhere. J Belg Soc Radiol. 2018; 102(1): 17, doi: 10.5334/jbsr.1354, indexed in Pubmed: 30039031.

34. Miller TT, Reinus WR. Nerve entrapment syndromes of the elbow, forearm, and wrist. Am J Roentgenol. 2010; 195(3): 585-594, doi: 10.2214/AJR.10.4817, indexed in Pubmed: 20729434.

35. Moore KL, Dalley AF, Agur AMR. Clinically Oriented Anatomy. Lippincott Williams\&Wilkins, Philadelphia 2013.

36. Moore KL, Dalley AF. Clinical Oriented Anatomy. Lippincott Williams\&Wilkins, Philadeplphia 1999.

37. Nakatani T, Tanaka S, Mizukami S. Bilateral four-headed biceps brachii muscles: the median nerve and brachial artery passing through a tunnel formed by a muscle slip from the accessory head. Clin Anat. 1998; 11(3): 209-212, doi: 10.1002/(SICI) 1098-2353(1998)11:3<209::AIDCA10>3.0.CO;2-N, indexed in Pubmed: 9579595.

38. Olewnik $t$, Podgórski M, Polguj $M$, et al. Anatomical variations of the pronator teres muscle in a Central European population and its clinical significance. Anat Sci Int. 2018; 93: 299-306.

39. Olewnik $\measuredangle$, Waśniewska A, Polguj M, et al. Morphological variability of the palmaris longus muscle in human fetuses. Surg Radiol Anat. 2018; 40(11): 1283-1291, doi: 10.1007/ s00276-018-2069-2, indexed in Pubmed: 30022223.

40. Olewnik $Ł$, Waśniewska A, Polguj $M$, et al. Rare combined variations of renal, suprarenal, phrenic and accessory hepatic arteries. Surg Radiol Anat. 2018; 40(7): 743-748, doi: 10.1007/s00276-018-2026-0, indexed in Pubmed: 29667030.

41. Olewnik $Ł$, Wysiadecki G, Polguj M, et al. Anatomical variations of the palmaris longus muscle including its relation to the median nerve - a proposal for a new classification. BMC Musculoskelet Disord. 2017; 18(1): 539, doi: 10.1186/ s12891-017-1901-x, indexed in Pubmed: 29258498.

42. Olewnik $Ł$, Wysiadecki G, Polguj M, et al. A rare anastomosis between the common hepatic artery and the superior mesenteric artery: a case report. Surg Radiol Anat. 2017; 39(10): 1175-1179, doi: 10.1007/s00276-017-1859-2, indexed in Pubmed: 28432408.

43. Pai MM, Nayak SR, Krishnamurthy A, et al. The accessory heads of flexor pollicis longus and flexor digitorum profundus: Incidence and morphology. Clin Anat. 2008; 21(3): 252-258, doi: 10.1002/ca.20612, indexed in Pubmed: 18351652.

44. Pećina M, Bojanić I. Musculocutaneous nerve entrapment in the upper arm. Int Orthop. 1993; 17(4): 232-234, doi: 10.1007/BF00194185, indexed in Pubmed: 8407039.

45. Podgórski M, Olewnik $Ł$, Rusinek $M$, et al. 'Superior biceps aponeurosis': Morphological characteristics of the origin of the short head of the biceps brachii muscle. Ann Anat. 2019; 223: 85-89, doi: 10.1016/j.aanat.2019.01.014, indexed in Pubmed: 30797975. 
46. Podgórski MT, Olewnik Ł, Grzelak P, et al. Rotator cable in pathological shoulders: comparison with normal anatomy in a cadaveric study. Anat Sci Int. 2019; 94(1): 53-57, doi: 10.1007/s12565-018-0447-9, indexed in Pubmed: 29987440.

47. R.Bardeen C. Development and variation of the musculature of the inferior extremity and the neighboring regions of the trunk in man. Am J Anat. 1907; 6(1): 259-390, doi: 10.1002/aja.1000060108.

48. Remerand F, Laulan J, Couvret $C$, et al. Is the musculocutaneous nerve really in the coracobrachialis muscle when performing an axillary block? An ultrasound study. Anesth Analg. 2010; 110: 1729-1734.

49. Rodríguez-Niedenführ M, Vázquez $T$, Choi $D$, et al. Supernumerary humeral heads of the biceps brachii muscle revisited. Clin Anat. 2003; 16(3): 197-203, doi: 10.1002/ ca.10060, indexed in Pubmed: 12673814.

50. Sargon MF, Tuncali D, Celik HH. An unusual origin for the accessory head of biceps brachii muscle. Clin Anat. 1996; 9(3): 160-162, doi: 10.1002/(SICI)10982353(1996)9:3<160::AID-CA4>3.0.CO;2-K, indexed in Pubmed: 8740475.

51. Wood J. On human muscular variations and their relation to comperative anatomy. J Anat Physiol. 1867; 1: 44-59.

52. Wood J. On some varieties in human myology. Proc R Soc, London 1864: 299-303.

53. Yershov D, Hudák R. Unusual Variation of the Biceps Brachii with Possible Median Nerve Entrapment. Prague Med Rep. 2015; 116(2): 167-172, doi: 10.14712/23362936.2015.55, indexed in Pubmed: 26093671. 